\title{
Optimization of the dimensional parameters of the working body for compaction temporary sprinkler dams
}

\author{
Maksud Karimov, Zayniddin Sharipov ${ }^{1 *}$, and Taxir Usmanov \\ Tashkent Institute of Irrigation and Agricultural Mechanization Engineers, Tashkent, Uzbekistan
}

\begin{abstract}
The article presents the results of research work to optimize the working dimensions of the sealing working bodies of the dammer. A skishaped sealing sheet and a cone roller are used as working elements to seal the outer and inner parts of the temporary sprinkler dam. The sealing sheet of the sliding working body compresses, thanks to the presence of the inclined cheek SH and eliminates the restoration of compacted soil with the EC section. When the sealing sheet moves along the surface of the dam slope, it is immersed under the action of its own weight or the pressure force of the additional loader (spring) by the value $h_{1}$, the soil layer with the thickness $h_{1}$ is pressed into the body of the dam. In this case, the nature of the impact of the compacting cheek of the face on the lump of soil depends on the value of the angle $\alpha$ l of its inclination to the horizon and the speed of movement. To seal the outer part of the dam, take a cone roller as a working body. To substantiate the parameters of the conical working body, conical working elements were manufactured with a change in the large diameter of the truncated cone and different sizes of sealing sheets. During operation, the roller rotates on its axis with sliding and has no torque on the shaft. To find out the effect of sliding on the value of the longitudinal movement of the compacted soil particles on the surface of the dam, the nature of the effect of the base of the conical part of the roller on them is graphically considered.
\end{abstract}

\section{Introduction}

It is known that until now, the main irrigation method for agricultural crops is the furrow irrigation method. To supply water from a permanent canal to irrigation furrows, temporary irrigation canals are cut using trenchers [7]. The density of the dam of a temporary sprinkler plays a role in the production of irrigation works. The soil density of a dam to a certain extent indicates its water-holding capacity. The higher the density of the dam soil, the less erosion.

The dams formed by existing trenchers are often washed away by water when temporary sprinklers are cut. The reason is the insufficient density of the dam soil; then, naturally, there is a need to increase it by compaction $[8,9]$.

The aim of the study is to study the process of filtration (erosion) of water depending on the soil compaction of the dam of a temporary sprinkler.

\footnotetext{
${ }^{1^{*}}$ Corresponding author: z.sharipov@tiiame.uz
} 


\section{Materials and Methods}

Analysis of theoretical prerequisites for the excavation of temporary irrigation ditches by existing canal diggers and the degree of dam compaction to reduce the soil filtration coefficient of irrigation dikes $[5,10,11]$.

Previously, studies were carried out to justify the parameters of the seal. However, their application in production experiments did not give the corresponding result.

Theoretical studies for calculating the main parameters of the channel cut by the canal diggers and the dampener are carried out using the general laws of mechanics [2, 4].

Experimental studies have shown that the condition of the dam soil, characterized by a density of $1.5 \mathrm{~g} / \mathrm{cm}^{3}$, does not allow its erosion (Table 1). Therefore, this state can be considered the lower limit of compaction, and in the future, when compaction of the bound soil of the dam, it is necessary to achieve these density values. In this case, the dam's height naturally decreases, and its value should provide the command water level $[6,8]$.

Table 1. Change in water filtration depending on soil compaction of a temporary sprinkler dam

\begin{tabular}{|c|c|c|c|}
\hline \multicolumn{2}{|c|}{ Dam soil densit $\mathrm{g} / \mathrm{cm}^{3}$} & \multirow{2}{*}{$\begin{array}{c}\text { Filtration } \\
\text { rate water, } \\
\text { cm/hour }\end{array}$} & $\begin{array}{c}\text { Cases of } \\
\text { dam } \\
\text { erosion }\end{array}$ \\
\hline $\begin{array}{c}\text { Inner half of } \\
\text { the dam }\end{array}$ & $\begin{array}{c}\text { Outer half } \\
\text { of the dam }\end{array}$ & 25.6 & 4 cases \\
\hline 0.9 & 0.9 & 16.3 & 1 case \\
\hline 1.2 & 1.2 & 11.4 & 0 \\
\hline 1.5 & 1.5 & 6.4 & 0 \\
\hline 1.7 & 1.7 & 11.6 & 0 \\
\hline 1.5 & 0.9 & 4.1 & 0 \\
\hline 1.8 & 1.3 & & \\
\hline
\end{tabular}

In addition, it turned out that basically, the inner half of the dam should be compacted to a greater extent than the outer (outer) part of it. If the inner half of the dam is compacted more than $1.8 \mathrm{~g} / \mathrm{cm}^{3}$, it is possible to leave the outer half unconsolidated.

Since mechanizing the sealing of dams of temporary irrigation ditches has not yet been resolved, work on sealing dams of temporary irrigation ditches is performed mainly manually.

Observations have confirmed that to ensure the specified irrigation rates and the command level, the height of the dams is necessary, and the existing canal diggers provide by increasing the depth of the temporary sprinkler, the level for which is located relative to the bottom of the irrigation furrows below $0.08 \ldots 0.24 \mathrm{~m}$. After the cessation of irrigation, part of the water remains, this is a net loss and negatively affects the quality of inter-row treatments [1-15].

To create a command level of water in a temporary sprinkler, it must be $5 \ldots 10 \mathrm{~cm}$ higher from the field surface. Then the normal mode of irrigation along the furrows will be ensured. Based on this, the required height of the dam for a temporary sprinkler should be at least $10 \ldots 15 \mathrm{~cm}$ from the surface of the field, to prevent water overflow through the dams, since insufficient height of the dam can lead to:

- overflow of water over the upper edge of the dam, resulting in erosion of the dam;

- an increase in labor costs and a decrease in the productivity of irrigators.

Therefore, the compaction of the soil of the dam of temporary irrigation ditches by an external force is the most active way of bringing particles closer together.

Proceeding from this, the density of temporary sprinkler dams plays a significant role in the production of irrigation works and shows its water-holding capacity.

There are different ways to increase density $[12,13]$.

1. 1.sealing;

2. the addition of sand or binders; 
3. reducing the size of the fraction and others.

It should be noted that earlier studies were carried out aimed at substantiating the parameters of the compactor of soil rollers cut during leaching and watering of saline soils. The use of this compactor for sealing dams of temporary sprinklers did not give the desired result without changing and justifying its main parameters.

It is known that compactors with sliding, rolling, and vibrating working bodies are used for soil and soil compaction [14].

Let us consider the technological process of operation of each type of sealing device from the point of view of soil compaction without protruding it onto the dams' surface, without their longitudinal and transverse movement.

The sealing sheet of the sliding working body (Figure 1) produces compaction due to the inclined cheek SH and eliminates the restoration of compacted soil with the EC section.

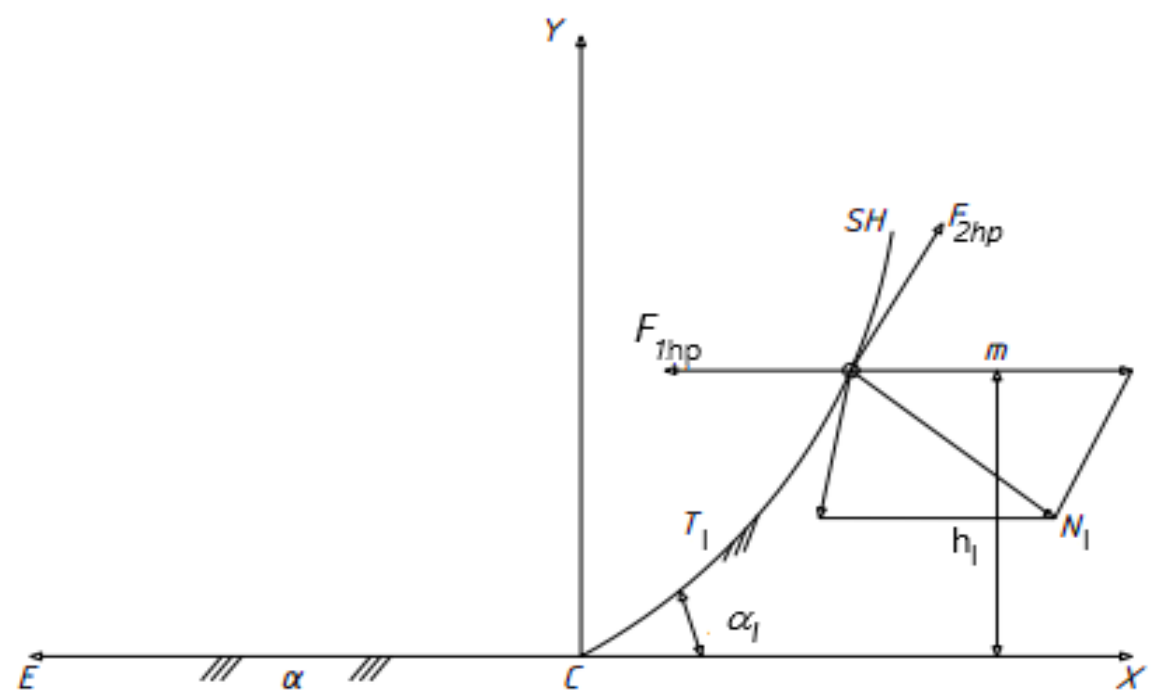

Fig. 1. Diagram of the interaction of the sealing sheet with the dam soil

When the sealing sheet moves along the surface of the dam slope, it is immersed under the action of its own weight or the pressure force of the additional loader (spring) by the value $h_{1}$, the soil layer with a thickness $h_{1}$ is pressed into the body of the dam. In this case, the nature of the impact of the compacting cheek of the face on the lump of soil depends on the value of the angle $\alpha_{1}$ of its inclination to the horizon and the speed of movement. [15].

A condition under which the soil of the dam is compacted with a sheet without shifting the soil particles in the direction of travel. Since only under this condition, there is no bulging, which causes the shedding of soil particles to the bottom of the channel.

Compaction without shedding the soil to the bottom of the channel is achieved when the angle formed by the vector of the velocity of movement of the compaction surface and the vector of normal pressure is less than the angle of external friction of the soil, at which the bulging is completely eliminated. This is facilitated by the ski-shaped outer sealing part of the damper compactor, which helps to retain the soil after it leaves the ditch dump.

To substantiate the parameters, skis were made with different length and width, which are shown in (Figure 2). 


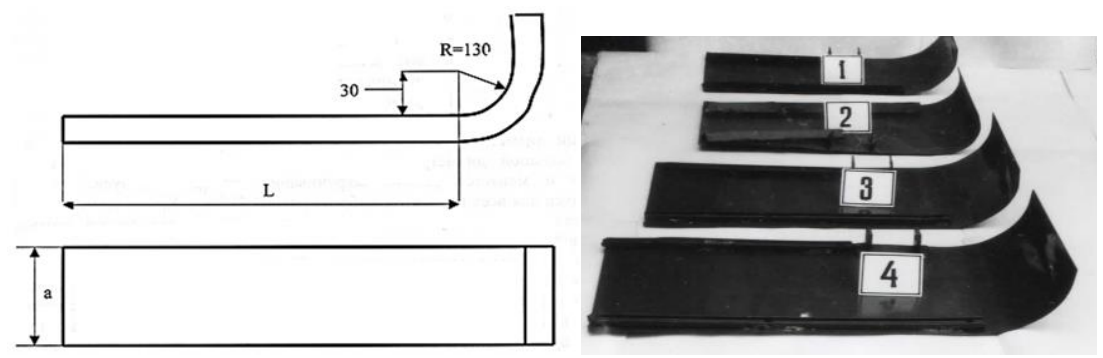

Fig 2. Dimmer ski scheme: $\mathrm{L}$ is the length of the ski, a is the width of the ski, $\mathrm{R}$ is the radius of curvature.

To seal the outer part of the dam, take a cone roller as a working body. To substantiate the parameters of the conical working body, conical working elements were made with a change in the large diameter of the truncated cone, which is shown in (Figure 3).
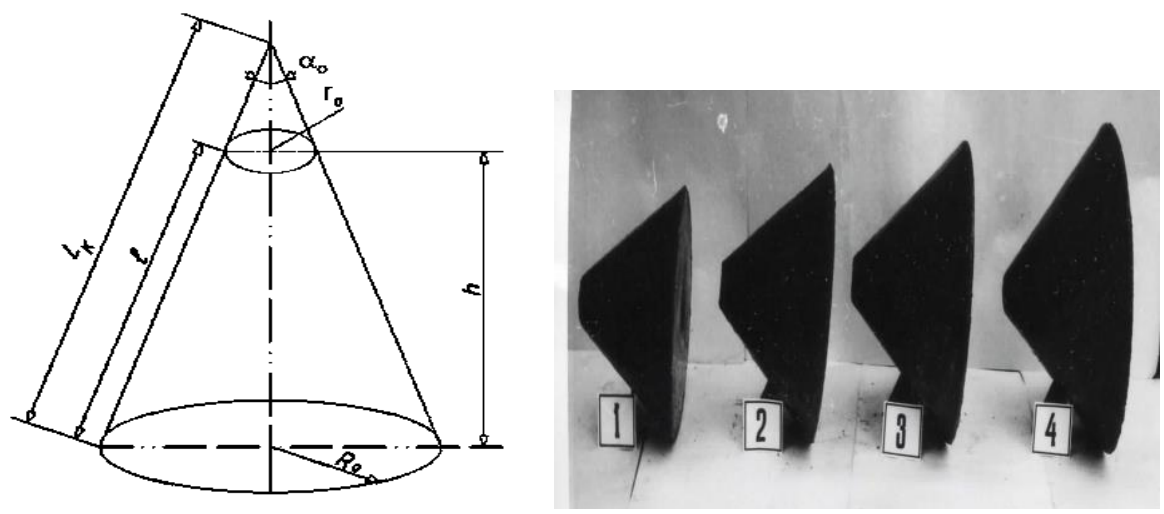

Fig. 3. Diagram of a conical working element

$R_{o}$ is a large radius of a truncated cone, $r_{o}$ is a small radius of a truncated cone, $\mathrm{h}$ is the height of the cone, 1 is the width of the sweep of the cone, $L$ is the radius of rounding of the sweep of the cone. During operation, the tapered roller rotates on its own axis with a slip characteristic of passive compacting rollers, i.e., having no torque on the shaft. To find out the effect of sliding on the value of the longitudinal movement of the compacted soil particles on the surface of the dam, we will graphically consider the nature of the effect of the base of the conical part of the roller on them. Suppose a tapered roller is sliding (Figure 2) $[15-20]$.

Expanding the force of normal pressure into the components $Q_{m}$ and $T_{m}$, we can assume the following if:

1. $T_{m} \leq F_{2}$, then the surface particle under the action of the force $Q_{m}$ moves more along the dam than inland;

2. $T_{m}>F_{2}$, then the resultant of external forces deviates from the normal pressure $N_{m}$ by an angle opposite the rotation of the roller. In this case, the longitudinal movement of surface soil $\mathbf{m m}^{\prime}$ particles will be greater than into the depth $Q^{\prime} \boldsymbol{m}^{\prime}$ of the dam;

3. It is not difficult to verify that the resultant of the $Q^{\prime}$ forces $T_{m}$ and $F$ is determined from the expression: 


$$
Q^{\prime}=N_{m}\left(\operatorname{tg} \beta-\operatorname{tg} \varphi_{2}\right)
$$

Whence it follows that the larger the angle $\beta$ and the smaller $\varphi_{2}$, i.e., the smoother the surface of the roller, the less it deviates from, $Q_{m}^{\prime}$ and the greater the $N_{m}$ immersion of soil particles into the depths of the dam. Consequently, the smallest soil compaction of the dam with sliding rollers is achieved at lower values of the angle of external soil friction.

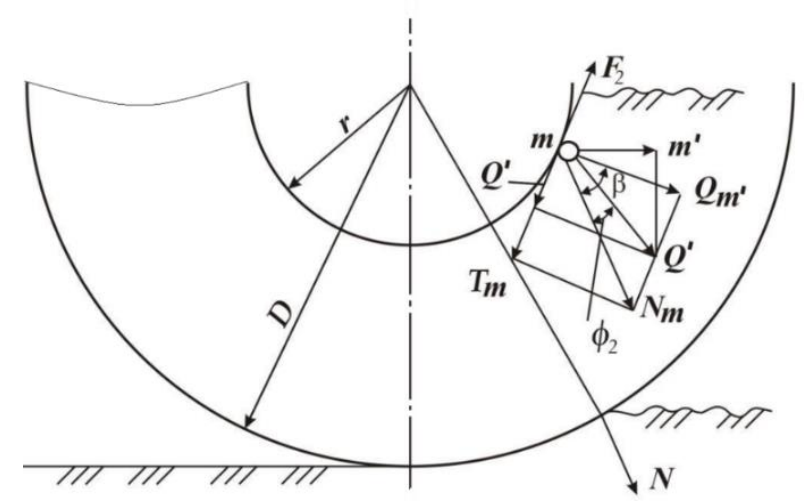

Fig 4. Scheme for substantiating the parameters of a cone roller

Let's say the conical part of the roller compresses the soil of the dam slopes. With the immersion depth of a large base $h_{b}$ and a small base $h_{m}$ (Figure 4).

$$
\operatorname{tg} \alpha=\frac{l^{\prime \prime}}{l} \quad l^{\prime \prime}=a^{k} a^{\prime} k-C_{k} C_{k}^{\prime}
$$

where $l^{\prime \prime}-$ is the length of the opposite leg, $\mathrm{m} ; \boldsymbol{l}-$ is length of the adjacent leg of the sealing advance angle, $\mathrm{m}$.

$$
l^{\prime \prime}=D \sin \alpha_{b}-r \sin \alpha_{m} \quad l=D-h_{b}-r \sin \alpha_{m}
$$

where $D$ and $\mathrm{r}$ are the radii of the large and small base of the truncated roller cone, $\mathrm{m}$. $\alpha_{b}$ and $\alpha_{m}$ are angles of immersion in the soil, deg. 


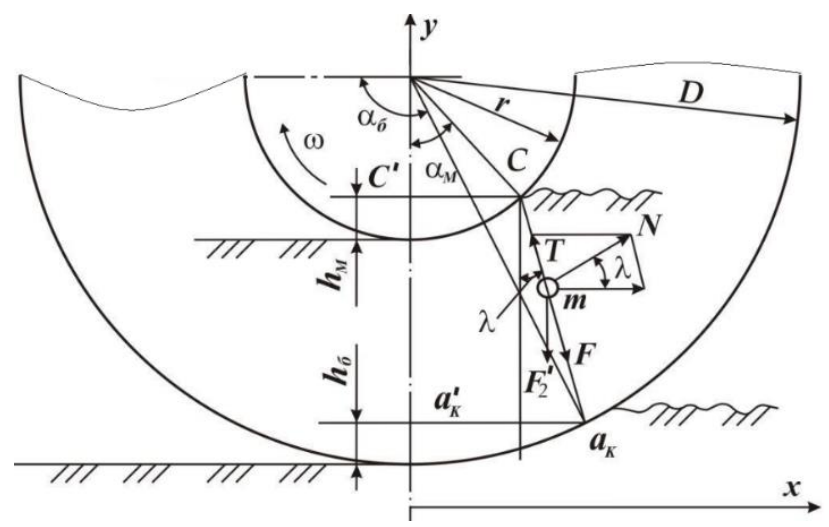

Fig. 5. To determine the lead angle of soil compaction conical roller on the embankment of the dam

Substituting the found values into the above formula, we obtain

$$
\operatorname{tg} \lambda=\frac{D \sin \alpha_{b}-r \sin \alpha_{m}}{D-h_{b}-r \cos \alpha_{m}}
$$

where $h_{b}$ is the immersion depth of the large base, $\mathrm{m}$.

$$
h_{b}=D-D \cos \alpha_{b}-R\left(1-\cos \alpha_{b}\right)=2 D \sin \frac{2 \alpha_{b}}{2}
$$

Hence:

$$
\operatorname{tg} \lambda=\frac{D \sin \alpha_{b}-r \sin \alpha_{m}}{D \cos \alpha_{b}-r \cos \alpha_{m}}
$$

If the immersion angles of the large and small bases are the same, i.e. $\sin \alpha_{b}=\alpha_{m}$, then:

$$
\operatorname{tg} \lambda=\operatorname{tg} \lambda
$$

This means that the angle of the advance of the compaction is equal to the angle of immersion of the roller base.

Therefore, according to equation (6), the greater the angle of immersion of the conical base of the roller, the greater the angle of the advance of the compaction:

$$
\begin{aligned}
& \cos \alpha_{b}=\frac{D-h_{b}}{D} \\
& \sin \alpha_{b}=\frac{1}{D} \sqrt{h_{b}\left(2 D-h_{b}\right)}
\end{aligned}
$$

Let's define in a similar way: 


$$
\begin{aligned}
\sin \alpha_{m}= & \frac{r-h_{m}}{r} \\
& \sin \alpha_{m}=\frac{r-h_{m}}{r} \\
\sin \alpha_{m}= & \frac{1}{2} \sqrt{h_{m}\left(2 r-h_{m}\right)}
\end{aligned}
$$

Substituting the values of the found quantities into formula (6) and after a series of transformations, we get:

$$
\operatorname{tg} \lambda=\frac{\sqrt{h_{b}\left(2 R-h_{b}\right)-h_{m}\left(2 r-h_{m}\right)}}{D-r-h_{b}+h_{m}}
$$

\section{Results and Discussion}

From expression (13), it follows that with an increase in the depth (hm) of immersion of the small base of the roller, the angle of the advance of the compaction decreases, and with an increase in the depth (h) of immersion of the large base of the roller, it increases. With an increase in the radius ( $\mathrm{r}$ ) of the small base, the angle of the advance of the compaction decreases, and with an increase in the radius (D) of the large base, it increases. If the immersion depth of both roller bases is the same, i.e., $h_{b}=h_{m}=h$, then formula (12) takes the form:

$$
\operatorname{tg} \lambda=\frac{\sqrt{h(2 D-h)-\left(2 r-h_{m}\right)}}{D-r}
$$

This means that the greater the difference between the radii of the large and small roller bases, the greater the angle of advance of the compaction.

Assuming the ice rink is stationary, i.e., $v=0$ and $Q=0$ using the limiting values of the angle, which will be equal $\lambda$ to the angle at which the crumbling of the dam $\varphi_{2}$ soil particles is completely eliminated, then in equality (13), it is possible to establish the relationship between the radii $\mathrm{D}$ and $\mathrm{r}$.

$$
R=\frac{\operatorname{tg} \varphi_{2} \cos \alpha_{m}-\sin \alpha_{m}}{\operatorname{tg} \varphi_{2} \cos \alpha_{b}-\sin \alpha_{b}} \cdot r
$$

The small diameter of the truncated cone was chosen equal to $60 \mathrm{~mm}$ for all variants, and the large diameter of the truncated cone had different values, respectively, and the radius of twisting of the sweep of the cone changes. The height of the truncated cone for all variants is chosen equal to $285 \mathrm{~mm}$. In addition, special lugs and plates are made on the frame of the damper compactor for easy replacement of the corresponding ski and cone working element. 
Experimental studies were carried out in the field. For which a site with a flat relief was chosen. Before conducting the experiments, irrigation furrows were cut and irrigated in the selected area. After watering, the field is loosened and milled.

During the field experiments, the moisture content of the soil, where the research was carried out, was on the soil horizons: $0 \ldots 5 \mathrm{~cm}, 13 \ldots 14.5 \% ; 5 \ldots 19 \mathrm{~cm} .14 .3 \ldots 15.8 \%$; $10 \ldots 15 \mathrm{~cm} .15 .6 \ldots 17.1 \% ; 15 \ldots 20 \mathrm{~cm} .16 \ldots 17.5 \%$

\section{Conclusions}

1. The condition of the dam soil, characterized by a density of $1.5 \mathrm{~g} / \mathrm{cm}^{3}$, does not allow its erosion, and it is generally necessary to more compact the inner half of the temporary irrigation dam.

2. To seal the dam of the temporary sprinkler, a tapered roller was selected to compact the inner part of the dam, and to compact the outer part of the dam, a ski-shaped plate with dimensions: large diameter of a cone roller $540 \mathrm{~mm}$, ski length $643 \mathrm{~mm}$, ski width $360 \mathrm{~mm}$ and an angle of the embrace of the dam 30 degrees.

3. The relationship between the angle of the advance of the compaction and the diameter of the tapered roller has been established, and analytical dependences have been derived to determine the large and small diameter of the tapered roller.

\section{References}

1. Bakhramov F.Kh. "Substantiation of the parameters of the working body of the canal digger for cutting temporary sprinklers, Tashkent, (1995)

2. Akalis M. Handbook of elementary matematics, mechanics and physics, pp. 215-220, (1995)

3. Scientific and technical report. Uzbek Scientific Research Institute of Agricultural Mechanization and Electrification (UEMEI), Tashkent, (1996)

4. Korn G., Korn T. Handbook of elementary matematics, for scientists and engineers. M., Sciense. (1990).

5. Adler Y.P., Markova E.V. "Planning experiments in the search for optimal conditions." Moscow (1976)

6. Vydenyapin G.V. General method of experimental research and processing of experimental data, M., Kolos. (1973).

7. Gorokhov V.I. Canal diggers and ditchers, M., Mashgiz. (1953)

8. Karimov M.S., Usmonov T.U., Baizakov T., Otamurodov G. To the determination of the main parameters of a damper sealer "Agroilm" № 1, (2020)

9. Shabanov D.K. Canal-dredger-furrower with leveler KBN-0.35A. The journal "Mechanization of cotton growing, № 11. pp. 12-15, (1974).

10. Autambaev M., Ivanov A.Z., Terekhov Y.I. "Basics of planning a research experiment, pp. 22-36, (1993)

11. Malnikov S.V., Aleshkin V.R., Roshin P.V. Planning experiments in research of agricultural processes, Leningrad, (1980).

12. Fenin N.K., Yasinetskiy V.G. Organization and technology of irrigation and drainage works, Publishing house of agricultural literature, (1963)

13. Pigulevsky M.Kh. Fundamentals and methods of studying the physical and mechanical properties of soil, Proceedings of the Leningrad Branch of the All-Russian Research Institute of Fertilizers, Agrotechnics and Agrosoil Science, № 44, (1936)

14. Kholodov A.M. Influence of the sliding motion of the rollers on soil compaction. Proceedings of HADI, 10, (1950) 
15. Dementyev B.G. Irrigation"Textbook", Moscow "Kolos" № 3, pp. 29-50, (1979).

16. Usmanov T.U. Theoretical substantiation of means for cleaning flume sprinklers from sediments, Tashkent, (2019)

17. Usmanov T.U. On the issue of siltation and cleaning of canals of reclamation systems" Collection of materials of the International Scientific and Practical Conference, pp.636-639, (2020)

18. Pulatov U.Y. Mechanization of maintenance and repair work in irrigation, Tashkent, (1988)

19. Usmanov T.U., Karimov M.S., Sharipov Z.Sh. To the determination of the main parameters of the dammer, International agricultural engineering" Scientific and technical journal, № 3, pp. 34-39, (2015)

20. Shumakov B.B. Melioration and water management. M., (1990) 